\title{
One-dimensional Pt nanofibers formed by the redox reaction at the ionic liquid|water interface
}

\author{
$\operatorname{AUTHOR}(S):$ \\ Zhang, Yu; Nishi, Naoya; Amano, Ken ichi; Sakka, \\ Tetsuo
}

\section{CITATION:}

Zhang, Yu ...[et al]. One-dimensional Pt nanofibers formed by the redox reaction at the ionic liquid|water interface. Electrochimica Acta 2018, 282: 886-891

\section{ISSUE DATE:}

2018-08-20

URL:

http://hdl.handle.net/2433/254668

\section{RIGHT:}

(C) 2018. This manuscript version is made available under the CC-BY-NC-ND 4.0 license http://creativecommons.org/licenses/by-nc-nd/4.0/.; This is not the published version. Please cite only the published version.; この論文は出版社版でありません。引用の際には 出版社版をご確認ご利用ください。 
One-dimensional Pt nanofibers formed by the redox reaction at the ionic liquid|water interface

Yu Zhang, ${ }^{[\mathrm{a}]}$ Naoya Nishi, ${ }^{* \mathrm{a}]}$ Ken-ichi Amano ${ }^{[\mathrm{a}]}$ and Tetsuo Sakka ${ }^{[\mathrm{a}]}$

[a] Y. Zhang, N. Nishi, K. Amano, T. Sakka

Department of Energy and Hydrocarbon Chemistry, Graduate School of Engineering, Kyoto University.

Kyoto 615-8510, Japan.

E-mail: nishi.naoya.7e@kyoto-u.ac.jp 


\begin{abstract}
Pt nanofibers have been prepared with a redox reaction occurring spacio-selectively at the liquid-liquid interface between a highly hydrophobic ionic liquid (IL) and water (W), which has been utilized as two dimensional reaction field. The preparation is conducted based on the concept of the coupling between ion transfer (IT) and electron transfer (ET) across the IL/W interface, which previously enabled direct formation of dendritic Au nanofibers at the IL/W interface (Chem. Commun., 2015, 51, 13638). The successful preparation of Pt nanofibers has manifested the generality of the IL/W interface method for the formation of metal nanofibers. Electrochemical measurements at the IL/W interface have confirmed that IT of $\mathrm{PtCl}_{4}{ }^{2-}$ from W to IL is actually coupled with ET between $\mathrm{PtCl}_{4}{ }^{2-}$ initially dissolved in $\mathrm{W}$ and decamethylferrocene in IL, leading to the spontaneous formation of Pt nanofibers at the IL/W interface. Herein, IT of $\mathrm{PtCl}_{4}{ }^{2-}$ ions from $\mathrm{W}$ to IL not merely neutralizes the excess charges generated in each liquid phase by ET, but also provides $\mathrm{PtCl}_{4}{ }^{2-}$ into $\mathrm{IL}$ as reactants for the growth of Pt nanofibers that takes place at the IL side of the IL/W interface. The electrocatalytic activity of the Pt nanofibers in oxygen reduction reaction (ORR) has also been evaluated.
\end{abstract}

Key words: liquid/liquid electrochemistry; ionic liquid|water interface, electron transfer; ion transfer; Pt nanofibers. 


\section{Introduction}

Noble-metal nanostructures have attracted considerable interests for their particular optical, electronic, magnetic and catalytic properties ${ }^{[1-4]}$. One dimensional (1D) noble-metal nanostructures such as nanowires, nanotubes, and nanofibers ${ }^{[5-7]}$, have tremendously large surface area and thus show high activity for catalysis ${ }^{[8]}$. Some literatures have reported that the network structures formed by nanofibers or nanowires facilitate the electron transport ${ }^{[9]}$, which provides crucial potential on applications such as catalyst, sensor and bioimaging ${ }^{[10-11]}$. Several approaches for synthesis of 1D noble-metal nanostructures have been developed ${ }^{[12-15]}$. However, most of these approaches require templates and consequently removal procedure of the templates $^{[16-18]}$. There still remain great challenges to directly synthesize 1D noblemetal nanostructures without the use of templates.

In our previous paper, we have reported a novel method to prepare Au nanofibers $^{[19]}$. This method is based on the oil (O)-water (W) two-phase system which has been widely used for preparation of metal nanoparticles over a century ${ }^{[20-26]}$. We adopted a A highly hydrophobic ionic liquid (IL) was adopted rather than a conventional organic solvent to prepare Au nanofibers, since the highly hydrophobic cation and anion constituting such an IL have high Gibbs energy of transfer into W, resulting in electrochemically polarizable IL/W interface with wide potential window $^{[27-28]}$. Therefore, such highly hydrophobic ILs enable us to perform electrochemical measurements at the IL/W interface by using the same method with that at the $\mathrm{O} \mid \mathrm{W}$ interface ${ }^{[29-32]}$.

Aside from these electrochemical advantages, ILs have designability of chemical structure of ions. Such designability could be beneficial for facet-selective 
growth of metal crystallites, providing a possibility to control the morphology of metal nanostructures by designing and adjusting IL-ions. Recently, Yao et al. prepared Ag films at the IL/W interface and demonstrated that the morphology is greatly affected by the used ILions $^{[33-34]}$. This fact was also confirmed by their recent work, where changing the kind of used IL-ions led Au nanostructures to form diverse morphology ${ }^{[35]}$. In addition, the particular physical properties of ILs which distinctly differ from conventional organic solvents could be favourable for the formation of unique nanostructures. For instance, the high viscosity of ILs can greatly limit the mass transfer rate of species in ILs and plays an important role for the formation of $1 \mathrm{D}$ nanostructures ${ }^{[36]}$. Chen et al. reported the preparation of nanostructures of Co, Pd and Pd-Co alloy at the IL/W interface, where ILs play an important role for controlling the surface appearance, size and structure of nanomaterials ${ }^{[37]}$. Kaminska et al. prepared Au nanoparticles by electrodeposition at the ITO|IL/W three phase contact line ${ }^{[38]}$. In our previous research ${ }^{[19]}$, we prepared Au nanofibers with dendrites at the tip and revealed the detailed formation mechanism where not only electron transfer (ET) but also ion transfer (IT) across the IL|W interface plays a critical role ${ }^{[19]}$.

Pt is one of the most intriguing elements due to its high catalytic ability and Pt 1D nanostructures show highly promising applications in the catalysis research field. Song et al. reported a synthesis method of Pt nanowire networks, using chemical reduction of a Pt complex with the formed wormlike micelles by cetyltrimethylammonium bromide as a soft template in the water-chloroform two-phase system ${ }^{[39]}$. Xia et al. reported a one-pot synthesis of ultrathin 1D nanowires by a facile solvothermal method ${ }^{[40]}$. The O-W two-phase system has been used for the formation of Pt nanoparticles ${ }^{[21-23,25-26,41]}$, but has not be explored for Pt 1D nanostructures. A facile and template-free method to prepare Pt nanofibers would be valuable, which we expected to be realized by utilizing the IL/W interface as was done for the preparation of Au nanofibers ${ }^{[19]}$. In the present study, we will show that Pt nanofibers can be successfully prepared via a spontaneous redox reaction at the IL $\mid \mathrm{W}$ interface, and 
that these Pt nanofibers exhibit excellent electrocatalytic activity for oxygen reduction reaction $(\mathrm{ORR})$.

\section{Experimental}

\subsection{Preparation of the Pt nanofibers}

The preparation of Pt nanofibers was performed as follows. For a typical synthesis, 1.5 $\mathrm{mL}$ of water containing $\mathrm{HCl}(0.1 \mathrm{M})$ and $\left(\mathrm{NH}_{4}\right)_{2} \mathrm{PtCl}_{4}(0.01 \mathrm{M}$, Sigma-Aldrich) was made contact with $0.5 \mathrm{~g}$ of IL trihexyltetradecylphosphoniumtetrakis(3,5-bis(trifluoromethyl) phenyl)borate ([THTDP $\left.{ }^{+}\right]\left[\mathrm{TFPB}^{-}\right]$, synthesis method is in Supporting Information). $5 \mathrm{mg}$ of decamethylferrocene (DMFc, Wako) was dissolved into IL as the reducing agent. The IL-W two-phase system was put into a thermostatic water bath at $70{ }^{\circ} \mathrm{C}$ since $\left[\mathrm{THTDP}^{+}\right]\left[\mathrm{TFPB}^{-}\right]$ is solid at room temperature. The $\mathrm{W}$ phase was purged by bubbling $\mathrm{N}_{2}$ to remove $\mathrm{O}_{2}$ and the reaction system was sealed because otherwise DMFc would be oxidized by the dissolved $\mathrm{O}_{2}$. A thin black layer was spontaneously generated at the IL/W interface after 3 days. The W phase was removed by pipette and then methanol was added to dissolve IL. After the washing processes by methanol dispersion and centrifugation repeated 10 times, the black platinum nanofibers was kept in a vacuum dryer.

\subsection{Electrochemical measurements}

A potentiostat (HECS972 with the headbox 972-1,Fuso) was used for ET and IT measurements, and the temperature was controlled at $70{ }^{\circ} \mathrm{C}$ by a thermostatic water bath. (1) IT of $\mathrm{PtCl}_{4}{ }^{2-}$

This measurement was carried out by using two-electrode system, as shown in Fig. 1 (Cell I). A micropipette with tip outer diameter of $10 \mu \mathrm{m}$ was filled with W phase (Fig. S1), and a platinum electrode was inserted into the micropipette. A glass tube with inner diameter of $0.5 \mathrm{~mm}$ was filled with $\mathrm{W}_{\text {ref }}$ (Fig. S1), and a $\mathrm{Ag} / \mathrm{AgCl}$ electrode was inserted into the 
glass pipette. The micropipette and glass tube were inserted into [THTDP $\left.{ }^{+}\right]\left[\mathrm{TFPB}^{-}\right]$so that a micro-IL/W interface was formed at the tip of micropipette, in order to minimize the effect of ohmic drop in IL bulk ${ }^{[42]}$.

(2) ET between DMFc and $\mathrm{PtCl}_{4}^{2-}$

The electron conductor separating oil-water (ECSOW) ${ }^{[43]}$ system was employed for this measurement, in which the O- and W-phases are separated by an electron conductor so that no IT process can take place. As shown in Fig. 1 (cell II), 5 mg DMFc was added into $0.5 \mathrm{~g}$ IL phase as the reducing agent. A Platinum wire and a platinum microelectrode with diameter of $10 \mu \mathrm{m}$ were immersed into water and IL respectively and connected by a conductive wire (Fig. S2). The use of Pt microelectrode greatly reduces the area of the Pt|IL interface to several orders of magnitude smaller than that of the Pt|W interface. The recorded current is limited by processes for the ET at the Pt|IL interface (mass transfer and redox reaction of $\left.\mathrm{DMFc} / \mathrm{DMFc}^{+}\right)$.

\subsection{SEM and EDX measurements}

Methanol suspension of the prepared Pt nanofibers was dropped onto a carbon tape adhering on a substrate, and the Pt nanofibers were observed by scanning electron microscope (SEM, ultra-55, Zeiss) equipped with energy dispersive $\mathrm{x}$-ray spectrometer (EDX).

\subsection{Electrocatalytic activity measurements of Pt nanofibers for ORR}

(1) Preparation of catalyst films on glassy carbon electrode (GCE).

A GCE surface with a diameter of $6 \mathrm{~mm}$ and a geometric area of $0.283 \mathrm{~cm}^{2}$ was polished with $\mathrm{Al}_{2} \mathrm{O}_{3}$ particle suspension on a moistened polishing cloth for 5 minutes to a mirror finish. The polished surface is rinsed with Milli-Q water, and then dried at room temperature in air. Pt nanofiber catalyst films were obtained by casting Pt nanofibers dispersed in 1-hexanol on the GCE surface. The loading amount for Pt nanofibers, or Pt black (Pt-354011, Nilaco) as a control, on the GCE surface was $14 \mu \mathrm{g} / \mathrm{cm}^{2} .15 \mu \mathrm{L}$ of $0.05 \mathrm{wt} \%$ Nafion/ethanol solution was 
dropped onto the GCE surface in order to protect the Pt nanofiber catalysts.

(2) Electrochemical measurements

(1) Measurement for electrochemical surface area (ECSA) of Pt nanofiber catalysts

Electrochemical cell was filled with $0.1 \mathrm{M} \mathrm{HClO}_{4}$ solution and de-oxygenated with a steady stream of $\mathrm{Ar}$ for 30 minutes. The temperature of water bath was $30^{\circ} \mathrm{C}$. The catalyst coated GCE (the working electrode) was attached to the shaft of the electrode rotator and inserted into the electrolyte solution. The reference electrode was reversible $\mathrm{H}_{2}$ electrode (RHE). Cyclic voltammograms (CVs) were recorded at a sweep rate of $50 \mathrm{mV} / \mathrm{s}$. The electrochemical active surface area (ECSA) of Pt nanofiber catalysts was evaluated by the integration of the current at the hydrogen adsorption/desorption region in the CVs after the double layer correction.

(2) Measurement for Pt mass-specific activity ( $\left.j_{\text {mass }}\right)$ and Pt area-specific activity $\left(j_{\mathrm{k}}\right)$

After CV measurements for ECSA, the saturation gas was switched from $\mathrm{Ar}$ to $\mathrm{O}_{2}$, and the electrolyte was saturated with $\mathrm{O}_{2}$ for 30 minutes. ORR polarization curves were obtained with the sweep rate of $50 \mathrm{mV} / \mathrm{s}$ and the rotation rate of GCE at $1600 \mathrm{rpm}$.

The mass-specific activities ( $j$ mass, knietic current normalized by the loading amount of catalyst) and the area-specific activities ( $j_{\mathrm{k}}$, kinetic current normalized by the ECSA of catalyst) were obtained from the kinetic current which was calculated from the ORR polarization curve at $E=0.9 \mathrm{~V}$, and the detailed calculation method is in Supporting Information.

\section{Results and discussion}

The synthesis method of Pt nanofibers is derived from the preparation of $\mathrm{Au}$ nanofibers in our previous study ${ }^{[19]}$, where Au nanofibers were deposited with the redox reaction spontaneously taking place at the IL/W interface. Nevertheless, we found that for Pt precursor, no interfacial reaction occurred at the IL/W interface in 
the case of using the IL trioctylmethylammoniumbis(nonafluorobutanesulfonyl) amide ([TOMA $\left.\left.{ }^{+}\right]\left[\mathrm{C}_{4} \mathrm{C}_{4} \mathrm{~N}^{-}\right]\right)$and the reducing agent tri-p-tolylamine (TPTA), which have been verified to be valid for preparation of Au nanofibers already. Spontaneous deposition of metal nanofibers at the IL/W interface results from the coupling of IT of metal precursor with ET between metal precursor and reducing agent ${ }^{[19]}$. Therefore, for the Pt case with the same combination, the standard potentials for IT and ET are different from those for the Au case and seem to deviate from the conditions for the spontaneous reaction. Pt nanofibers were successfully prepared after two essential improvements were carried out. One is the replacement of $\left[\mathrm{TOMA}^{+}\right]\left[\mathrm{C}_{4} \mathrm{C}_{4} \mathrm{~N}^{-}\right]$by $\left[\mathrm{THTDP}^{+}\right]\left[\mathrm{TFPB}^{-}\right]$, which has even higher hydrophobicity, and thus can provide broader potential window at the IL/W interface ${ }^{[44]}$. The other is the replacement of mild reducing agent (TPTA) to a stronger one DMFc, since the stronger reducing agent leads the reduction reaction of Pt easier to take place and to be coupled with IT of Pt precursor ion from W to IL. Discussion of the standard Gibbs energies of four redox reactions taking place between two metal complexes $\left(\mathrm{PtCl}_{4}{ }^{2-}\right.$ and $\left.\mathrm{AuCl}_{4}{ }^{-}\right)$and two reducing agents (TPTA, DMFc) is in Supporting Information. For the improved approaches we used here, DMFc as the reducing agent was dissolved in [THTDP $\left.{ }^{+}\right]\left[\mathrm{TFPB}^{-}\right]$and $\left(\mathrm{NH}_{4}\right)_{2} \mathrm{PtCl}_{4}$ was dissolved in an aqueous solution of $\mathrm{HCl}$ to form $\mathrm{PtCl}_{4}{ }^{2-}$ in $\mathrm{W}$ as the metal precursor. Pt nanofibers were spontaneously formed at the IL $\mid \mathrm{W}$ interface, demonstrating that the IL/W interface method can be utilized as a general strategy for the synthesis of $1 \mathrm{D}$ noble-metal nanofibers, and the accuracy of the proposed mechanism was also verified. The revealed mechanism can be utilized as a guideline for the synthesis of other metal nanostructures in the IL-W system.

To understand the formation mechanism of Pt nanofibers, electrochemical measurements of IT and ET across the IL/W interface were carried out. CVs at the IL/W interface for IT measurements were performed by using Cell I (Supporting Information) in 
the absence of reducing agent DMFc. Figure 2a shows the IT behaviour of $\mathrm{PtCl}_{4}{ }^{2-}$ across the IL/W interface from W to IL and IL to W, respectively, as described in eqn (1):

$\mathrm{PtCl}_{4}^{2-}(\mathrm{W}) \rightleftarrows \mathrm{PtCl}_{4}^{2-}(\mathrm{IL})$

The midpoint potential (approximately equal to half-wave potential) of IT of $\mathrm{PtCl}_{4}{ }^{2-}$ is shown as the black dashed line in Fig. 2a, which is around $30 \mathrm{mV}^{\text {. TFPB }}$, a highly hydrophobic anion, which constitutes $\left[\mathrm{THTDP}^{+}\right]\left[\mathrm{TFPB}^{-}\right]$adopted in the present study, provides a significantly broad potential window in positive potential region with width of $800 \mathrm{mV}$. In contrast, the anion $\mathrm{C}_{4} \mathrm{C}_{4} \mathrm{~N}^{-}$constituting $\left[\mathrm{TOMA}^{+}\right]\left[\mathrm{C}_{4} \mathrm{C}_{4} \mathrm{~N}^{-}\right]$that was used in the synthesis of $\mathrm{Au}$ nanofibers ${ }^{[19]}$, is not as hydrophobic as $\mathrm{TFPB}^{-}$, resulting in a narrower potential window, and thereby, limiting IT of $\mathrm{PtCl}_{4}{ }^{2-}$ that cannot spontaneously take place at the $\left[\mathrm{TOMA}^{+}\right]\left[\mathrm{C}_{4} \mathrm{C}_{4} \mathrm{~N}^{-}\right] \mid \mathrm{W}$ interface.

The ECSOW ${ }^{[43]}$ system was employed to investigate the ET between $\mathrm{PtCl}_{4}{ }^{2-}$ and DMFc. IT process are absolutely prevented since IL and W are separated but electrically connected by a metal. Figure $2 \mathrm{~b}$ shows the CV of ET whose current is limited by redox reaction process of $\mathrm{DMFc}^{+} / \mathrm{DMFc}$. The midpoint potential for the ET is around $-180 \mathrm{mV}$ shown as the red dashed line, which indicates that the redox reaction between $\mathrm{PtCl}_{4}{ }^{2-}$ and $\mathrm{DMFc}$ is significantly easier to take place, compared with the redox reaction between $\mathrm{PtCl}_{4}{ }^{2-}$ and TPTA (the midpoint potential is $210 \mathrm{mV}$, data is not shown). The net ET reaction between DMFc and $\mathrm{PtCl}_{4}{ }^{2-}$ is

$2 \mathrm{DMFc}(\mathrm{IL})+\mathrm{PtCl}_{4}^{2-}(\mathrm{W}) \rightarrow 2 \mathrm{DMFc}^{+}(\mathrm{IL})+\mathrm{Pt}+4 \mathrm{Cl}^{-}(\mathrm{W})$

The eqn (2) is not charge-balanced for each IL and W phase, indicating that actually eqn (2) can never take place individually without electrochemical systems or 
other charge transfer reactions coupling with it, both of which keep the charge balance of the two phases. In the present case, the ET can spontaneously occur by coupling with the IT of $\mathrm{PtCl}_{4}{ }^{2-}$ from $\mathrm{W}$ to IL to balance the electron neutrality of the two phases. $180 \mathrm{mV}$ ), the IT (1) and the ET (2) can couple and simultaneously proceed as described in eqn (3):

$2 \mathrm{DMFc}(\mathrm{IL})+2 \mathrm{PtCl}_{4}{ }^{2-}(\mathrm{W}) \rightarrow 2 \mathrm{DMFc}^{+}(\mathrm{IL})+\mathrm{Pt}+4 \mathrm{Cl}^{-}(\mathrm{W})+\mathrm{PtCl}_{4}{ }^{2-}(\mathrm{IL})(3)$

In order to verify the occurring of this spontaneous reaction, CV using Cell I with the presence of DMFc ( $50 \mathrm{mM}$ ) in IL was performed, and thus the both ET and IT can be recorded simultaneously. As shown in Fig. 2c, the CV shows non-polarized behavior, where ET (IT) is dominated at positive (negative) current region, and at even zero current potential, ET and IT spontaneously takes place.

Fig. 3a shows the scanning electron microscope (SEM) images of the obtained deposit by a typical synthesis. The deposit consists of nanofibers with a diameter of $30 \sim 100 \mathrm{~nm}$ and a length of 10 20 $\mu \mathrm{m}$, showing highly flexible and uniform 1D nanostructures. Surprisingly, these long and slender nanostructures have good stability in nano scale, against agglomeration. The EDX analysis (Fig. S6) was performed simultaneously with SEM measurements and detected only X-ray fluorescence of Pt, indicating that nanofibers are fully made of Pt metal.

To investigate the growth situation of the Pt nanofibers, the Pt nanofibers formed at the IL/W interface were immobilized by solidification of either of IL or W (the preparation method is in Supporting Information) and measured by SEM from the IL or $\mathrm{W}$ side. Figs. 3b and 3c show the $\mathrm{W}$ side and IL side of the Pt nanofibers, respectively. In Fig. 3b, for the Pt nanofibers at the $\mathrm{W}$ side, particles were observed at the ends of the nanofibers. The other side of the nanofibers are buried into the 
solidified IL and gradually fade away, indicating that these particles are exposed outside the solidified IL, in other words, formed at the W side of the interface and that these nanofibers are inside the solidified IL, which means that they are formed in IL. This result is reinforced by the observation of the IL side. No particle but only nanofibers can be observed at the IL side in Fig. 3c, demonstrating that the nanofibers are formed in IL, while the particles at the ends of nanofibers are formed in W. It is implied that the reduction of Pt were primarily completed inside IL, albeit the strong hydrophobicity of IL is likely to hinder the release of $\mathrm{Cl}^{-}$ions from $\mathrm{PtCl}_{4}{ }^{2-}$. However, the redox reaction taking place at IL/W interface is accompanied by the transfer of liberated $\mathrm{Cl}^{-}$ions from $\mathrm{IL}$ to $\mathrm{W}$, eventually promoting the reduction of $\mathrm{PtCl}_{4}{ }^{2-}$ on the IL side of the interface, as $\mathrm{Cl}^{-}$ions scarcely accumulated in the IL phase. The above results and our recent study ${ }^{[45]}$ have revealed that metal nanofibers are actually formed on the IL side of the IL/W interface, suggesting the occurrence of reduction of the metal complexes in the IL.The growth situation of the Pt nanofibers in both W and IL is schematically shown as Fig. 3d, the Pt nanostructures grow towards W as particles and towards IL as nanofibers. Moreover, Pt can deliver electrons as a conductor, and thereby, $\mathrm{PtCl}_{4}{ }^{2-}$ can be reduced without directly contacting with DMFc, the reducing agent in IL.

With respect to the reason why nanofibers are formed only in IL, it can be explained by high viscosity of IL, which is regarded as an important factor for the formation of 1D structure. This viewpoint was firstly proposed by Scholz and Hasse ${ }^{[36]}$, who suggested that the high viscosity of oil phase can cause great imbalance of mass transfer rates for metal precursor ions for $\mathrm{W}$ phase and reducing agent species for $\mathrm{O}$ phase. In the case of the present study, the viscosity of IL is thousands of times higher than W, which leads to Pt nanofibers growing towards IL phase so that they can enlarge the surface area and reduce the imbalance of mass transfer rates. Additionally, 
control experiments in our previous report ${ }^{[46]}$ have supported the model proposed by Scholz and Hasse ${ }^{[36]}$. The high viscosity is one of the factors for giving rise to nanofibers. Another factor is IL itself, which was found to induce the formation of nanofibers as well. Consequently, the formation of nanofibers is likely to arise from synergistic effect of high viscosity and IL itself (see Supporting Information for the details).

The application performance of Pt nanofibers for proton exchange membrane fuel cells (PEMFCs) was evaluated by measuring the electrocatalytic activity of Pt nanofibers toward ORR. As a comparison, commercial Pt black catalysts were also tested. Fig. S7 shows CVs for Pt nanofibers and Pt black loaded on a GCE in an Arpurged $0.1 \mathrm{M} \mathrm{HClO}_{4}$ solution. The ECSA was estimated from hydrogen adsorption current appeared in the CVs. ECSA of Pt nanofibers was found to be $6.2 \mathrm{~m}^{2} / \mathrm{g}$, which is $51 \%$ of Pt black catalyst $\left(12.1 \mathrm{~m}^{2} / \mathrm{g}\right)$. The relatively low ECSA for Pt nanofibers is most likely due to the intrinsic 1D morphology of nanofibers compared with 0D morphology of nanoparticles.

The ORR polarization curves for Pt nanofibers were recorded in an $\mathrm{O}_{2}$-saturated $0.1 \mathrm{M}$ $\mathrm{HClO}_{4}$ solution, as shown in Fig. S8. The Pt nanofibers exhibited a comparable mass-specific activity $\left(j_{\text {mass }}\right)$ with Pt black catalysts at $0.9 \mathrm{~V}(0.027 \mathrm{~mA} / \mu \mathrm{g}$ for Pt nanofibers, $0.030 \mathrm{~mA} / \mu \mathrm{g}$ for Pt black), and improved area specific activity $j_{\mathrm{k}}$, (kinetic current per unit surface area of catalyst, $0.43 \mathrm{~mA} / \mathrm{cm}^{2}$ for Pt nanofibers, $0.25 \mathrm{~mA} / \mathrm{cm}^{2}$ for Pt black), which is 1.7 times higher than Pt black. The high area-specific activity is related to the network structures that formed by Pt nanofibers. For a nanoscale structures, the agglomeration and self-assembled behavior is inevitable more or less. Nevertheless, 1D nanofibers with high flexibility twined and crossed to each other by self-assembling and consequently formed an extremely dense and complicated network structures to facilitate electron transport in nanoscale. This is distinguishable from the 
agglomeration of 0D particles which just form a bigger block of Pt, hence lowering the number of active sites of Pt surface.

\section{Conclusion}

In conclusion, we successfully prepared Pt nanofibers by improving the IL/W two-phase method, demonstrating that this is a general strategy for the synthesis of 1D metal nanofibers. By employing IT and ET voltammetry at the IL/W interface, the mechanism for the formation of Pt nanofibers was revealed from an electrochemical perspective: the spontaneous reaction can be decomposed to the IT of $\mathrm{PtCl}_{4}{ }^{2-}$ and the ET between DMFc and $\mathrm{PtCl}_{4}{ }^{2-}$ across the IL/W interface, and the precondition for spontaneous deposition at IL/W depends on whether IT and ET can be coupled. The electrocatalytic measurements of the Pt nanofibers for ORR revealed that the Pt nanofibers shows good prospect on PEMFCs field.

\section{Acknowledgements}

We acknowledge the assistance of Drs. Kohei Miyazaki and Atsunori Ikezawa for the ORR measurements. This work was partly supported by JSPS KAKENHI (Nos. 26410149, 26248004, 16H04216).

\section{References}

[1] R. K. Leary, A. Kumar, P. J. Straney, S. M. Collins, S. Yazdi, R. E. Dunin-Borkowski, P. A. Midgley, J. E. Millstone and E. Ringe, Structural and optical properties of discrete dendritic Pt nanoparticles on colloidal Au nanoprisms, J. Phys. Chem. C, 120 (2016) 20843-20851. 
[2] X. Teng, W.-Q. Han, W. Ku and M. Hücker, Synthesis of ultrathin palladium and platinum nanowires and a study of their magnetic properties, Angew. Chem. Int. E., 120 (2008) 2085-2088.

[3] L. Cademartiri and G. A. Ozin, Ultrathin nanowires-a materials chemistry perspective, Adv. Mater., 21 (2009) 1013-1020.

[4] B. Y. Xia, H. B. Wu, Y. Yan, X. W. Lou and X. Wang, Ultrathin and ultralong singlecrystal platinum nanowire assemblies with highly stable electrocatalytic activity, J. Am. Chem. Soc., 135 (2013) 9480-9485.

[5] J. Chen, T. Herricks, M. Geissler and Y. Xia, Single-crystal nanowires of platinum can be synthesized by controlling the reaction rate of a polyol process, J. Am. Chem. Soc., 126 (2004) 10854-10855.

[6] X. Zhang, D. Dong, D. Li, T. Williams, H. Wang and P. A. Webley, Direct electrodeposition of Pt nanotube arrays and their enhanced electrocatalytic activities, Electrochem. Commun., 11 (2009) 190-193.

[7] Y. Bi and G. Lu, Facile synthesis of platinum nanofiber/nanotube junction structures at room temperature, Chem. Mater.,20 (2008) 1224-1226.

[8] S. Kuchibhatla, A. S. Karakoti, D. Bera and S. Seal, One dimensional nanostructured materials, Prog. Mater. Sci., 52 (2007) 699-931.

[9] H. Liang, X. Cao, F. Zhou, C. Cui, W. Zhang and S. Yu, A Free - Standing Pt Nanowire Membrane as a Highly Stable Electrocatalyst for the Oxygen Reduction Reaction, Adv. Mater., 23 (2011) 1467-1471.

[10] S. E. Lohse and C. J. Murphy, The quest for shape control: a history of gold nanorod synthesis, Chem. Mater., 25 (2013) 1250-1261.

[11] E. C. Walter, F. Favier and R. M. Penner, Palladium mesowire arrays for fast hydrogen sensors and hydrogen-actuated switches, Anal. Chem., 74 (2002) 15461553. 
[12] J. Chen, Y. Xiong, Y. Yin and Y. Xia, Pt Nanoparticles Surfactant - Directed Assembled into Colloidal Spheres and used as Substrates in Forming Pt Nanorods and Nanowires, Small., 2 (2006) 1340-1343.

[13] L. Tiano, C. Koenigsmann, A. C. Santulli and S. S. Wong, Solution-based synthetic strategies for one-dimensional metal-containing nanostructures, Chem. Commun., 46 (2010) 8093-8130.

[14] Y. Sakamoto, A. Fukuoka, T. Higuchi, N. Shimomura, S. Inagaki and M. Ichikawa, Synthesis of Platinum Nanowires in Organic- Inorganic Mesoporous Silica Templates by Photoreduction: Formation Mechanism and Isolation, J. Phys. Chem. B, 108 (2004) 853-858.

[15] S. Sun, F. Jaouen and J. Dodelet, Controlled growth of Pt nanowires on carbon nanospheres and their enhanced performance as electrocatalysts in PEM fuel cells, Adv. Mater., 20 (2008) 3900-3904.

[16] Y. Song, R. M. Garcia, R. M. Dorin, H. Wang, Y. Qiu, E. N. Coker, W. A. Steen, J. E. Miller and J. A. Shelnutt, Synthesis of platinum nanowire networks using a soft template, Nano Lett., 7 (2007) 3650-3655.

[17] Y. Xia, P. Yang, Y. Sun, Y. Wu, B. Mayers, B. Gates, Y. Yin, F. Kim and Y. Yan, One - dimensional nanostructures: synthesis, characterization, and applications, Adv. Mater., 15 (2003) 353-389.

[18] H. Wang and L. Qi, Controlled synthesis of $\mathrm{Ag}_{2} \mathrm{~S}, \mathrm{Ag}_{2} \mathrm{Se}$, and Ag nanofibers by using a general sacrificial template and their application in electronic device fabrication, Adv. Funct. Mater.,18 (2008) 1249-1256.

[19] N. Nishi, T. Kakinami and T. Sakka, Dendritic nanofibers of gold formed by the electron transfer at the interface between water and a highly hydrophobic ionic liquid, Chem.Commun., 51 (2015) 13638-13641. 
[20] M. Brust, M. Walker, D. Bethell, D. Schiffrin and R. Whyman, Synthesis of Thiolderivatised Gold Nanoparticles in a Two-phase Liquid-Liquid System, J. Chem. Soc., Chem. Commun., 1994, 801-802.

[21] M. Platt, R. A.W. Dryfe and E. P.L. Roberts, Structural and electrochemical characterisation of Pt and Pd nanoparticles electrodeposited at the liquid/liquid interface, Electrochimica. Acta., 49 (2004) 3937-3945.

[22] M. Plattz and R. A. W. Dryfe, Structural and electrochemical characterisation of Pt and Pd nanoparticles electrodeposited at the liquid/liquid interface: Part 2, Phys. Chem. Chem. Phys., 7 (2005) 1807-1814.

[23] J. J. Nieminen, I. Hatay, P. Ge, M. A. Méndez, L. Murtomäki and H. H. Girault, Hydrogen evolution catalyzed by electrodeposited nanoparticles at the liquid/liquid interface, Chem.Commun.,47 (2001) 5548-5550.

[24] Y. Cheng and D.J. Schiffrin, Electrodeposition of metallic gold clusters at the water/1, 2-dichloroethane interface, J. Chem. Soc., Faraday Trans., 92 (1996) 38653871.

[25] Trojánek, J. Langmaier and Z. Samec, Random nucleation and growth of Pt nanoparticles at the polarised interface between two immiscible electrolyte solutions, J. Electroanal. Chem., 599 (2007) 160-166.

[26] S. J. Hoseini, N. Mousavi, M. Roushani, L. Mosaddeghi, M. Bahrami and M. Rashidi, Thin film formation of platinum nanoparticles at oil-water interface, using organoplatinum (II) complexes, suitable for electro-oxidation of methanol, Dalton Trans., 42 (2013) 12364-12369.

[27] T. Kakiuchi and N. Tsujioka, Cyclic voltammetry of ion transfer across the polarized interface between the organic molten salt and the aqueous solution, Electrochem. Commun., 5 (2003) 253-256. 
[28] H. Katano and H. Tatsumi, Ion-Transfer Voltammetry at a Polarized RoomTemperature Molten Salt | Water Interface, Anal. Sci., 19 (2003) 651-652.

[29] Z. Samec, Dynamic electrochemistry at the interface between two immiscible electrolytes, Electrochim. Acta., 84 (2012) 21-28.

[30] R. A. W. Dryfe, in Advances in Chemical Physics, ed. S. A. Rice, Wiley, New York, 141 (2009) p. 153.

[31] T. Kakiuchi, N. Tsujioka, K. Sueishi, N. Nishi and M. Yamamoto, Polarized potential window available at the interface between an aqueous electrolyte solution and tetraalkylammonium imide salts, Electrochemistry, 72 (2004) 833-835.

[32] Z. Samec, J. Langmaier and T. Kakiuchi, Charge-transfer processes at the interface between hydrophobic ionic liquid and water, Pure Appl. Chem., 81 (2009) 14731488.

[33] K. Yao, W. Lu, X. Li, J. Wang and J. Yuan, Tunable synthesis of Ag films at ionic liquid-aqueous interfaces, Chem. Commun., 49 (2013) 1398-1400.

[34] K. Yao, L. Li, X. Li, W. Lu, A. Xu, H. Zhang and J. Wang, Tunable synthesis of Ag films at the interface of ionic liquids and water by changing cationic structures of ionic liquids, Cryst. Growth., 17 (2017) 990-999.

[35] K. Yao, Q. Hang, W. Lu, A. Xu, X. Li, H. Zhang and J. Wang, A facile synthesis of gold micro/nanostructures at the interface of 1, 3-dibutylimidazolium bis (trifluoromethylsulfonyl) imide and water, J. Colloid Interface Sci., 480 (2016) 3038.

[36] F. Scholz and U. Hasse, Controlling the morphology of silver deposition at liquid| liquid interfaces: From nano-wires to super smooth films, Electrochem. Commun., 7 (2005) 541-546. 
[37] Y. Chen, M. Chen, J. Shi, J. Yang and D. Zhang, Fabrication of “clean” nanostructured metal materials on ionic liquid/water interface, Mater. Lett., 132 (2014) 153-156.

[38] Kaminska, J. Niedziolka-Jonsson, A. Roguska and M. Opallo, Electrodeposition of gold nanoparticles at a solid| ionic liquid| aqueous electrolyte three-phase junction, Electrochem. Commun., 12 (2010) 1742-1745.

[39] Y. Song, R. Garcia, R. Dorin, H. Wang, Y. Qiu, E. Coker, W. Steen, J. Miller and J. Shelnutt, Synthesis of platinum nanowire networks using a soft template, Nano Lett., 7 (2007) 3650-3655.

[40] B. Xia, H. Wu, Y. Yan, X. Lou and X. Wang, Ultrathin and ultralong single-crystal platinum nanowire assemblies with highly stable electrocatalytic activity, J. Am. Chem. Soc., 135 (2013) 9480-9485.

[41] Trojánek, J. Langmaier and Z. Samec, Electrocatalysis of the oxygen reduction at a polarised interface between two immiscible electrolyte solutions by electrochemically generated Pt particles, Electrochem. Commun., 8 (2006) 475-481.

[42] N. Nishi, S. Imakura and T. Kakiuchi, A digital simulation study of steady-state voltammograms for the ion transfer across the liquid-liquid interface formed at the orifice of a micropipette, J. Electroanal. Chem., 621 (2008) 297-303.

[43] H. Hotta, N. Akagi, T. Sugihara, S. Ichikawa and T. Osakai, Electron-conductor separating oil-water (ECSOW) system: a new strategy for characterizing electrontransfer processes at the oil/water interface, Electrochem. Commun., 4 (2002) 472477.

[44] N. Nishi, S. Imakura and T. Kakiuchi, Wide electrochemical window at the interface between water and a hydrophobic room-temperature ionic liquid of tetrakis [3, 5-bis (trifluoromethyl) phenyl] borate, Anal. Chem., 78 (2006) 2726-2731. 
[45] N. Nishi, I. Yajima, K. Amano, and T. Sakka, Janus-Type Gold/Polythiophene Composites Formed via Redox Reaction at the Ionic Liquid|Water Interface, Langmuir, 34 (2018) 2441-2447.

[46] T. Kakinami, N. Nishi and T. Sakka, Preparation of Dendritic Gold Nanofibers Using a Redox Reaction at the Interface between an Ionic Liquid and Water: Correlation between Viscosity and nanostructure, Bunsekikagaku, 5 (2016) 157-161.

\section{Cell I}

\begin{tabular}{c|c|c||c|c}
$(\mathrm{RE})$ & $(\mathrm{W})$ & $(\mathrm{IL})$ & $(\mathrm{W})$ & $(\mathrm{RE})$ \\
$\mathrm{Ag} / \mathrm{AgCl}$ & $\mathrm{LiCl} 0.1 \mathrm{M}$ & $\left.\mathrm{THTDP}^{+}\right]\left[\mathrm{TFPB}^{-}\right]$ & $\mathrm{HCl}^{0.1 \mathrm{M}}$ & \\
$\mathrm{PtCl}_{4}^{2-}$ & $0.01 \mathrm{M}$ & $\mathrm{Pt}$
\end{tabular}

Cell II

\begin{tabular}{|c|c|c|c|c|}
\hline (RE) & (W) & (IL) & & (W) \\
\hline $\mathrm{Ag} / \mathrm{AgCl}$ & $\mathrm{LiCl} 0.1 \mathrm{M}$ & DMFc $0.05 \mathrm{M}$ & Pt & $\mathrm{HCl} 0.1 \mathrm{M}$ \\
\hline & THTDPCl $0.001 \mathrm{M}$ & [THTDP $\left.^{+}\right]\left[\right.$TFPB $\left.^{-}\right]$ & & $\mathrm{PtCl}_{4}^{2-} 0.01 \mathrm{M}$ \\
\hline
\end{tabular}

Figure 1. The cell configuration of (cell I) ion transfer measurement of $\mathrm{PtCl}_{4}{ }^{2-}$ and (cell II) electron transfer measurement between DMFc and $\mathrm{PtCl}_{4}^{2-}$. 


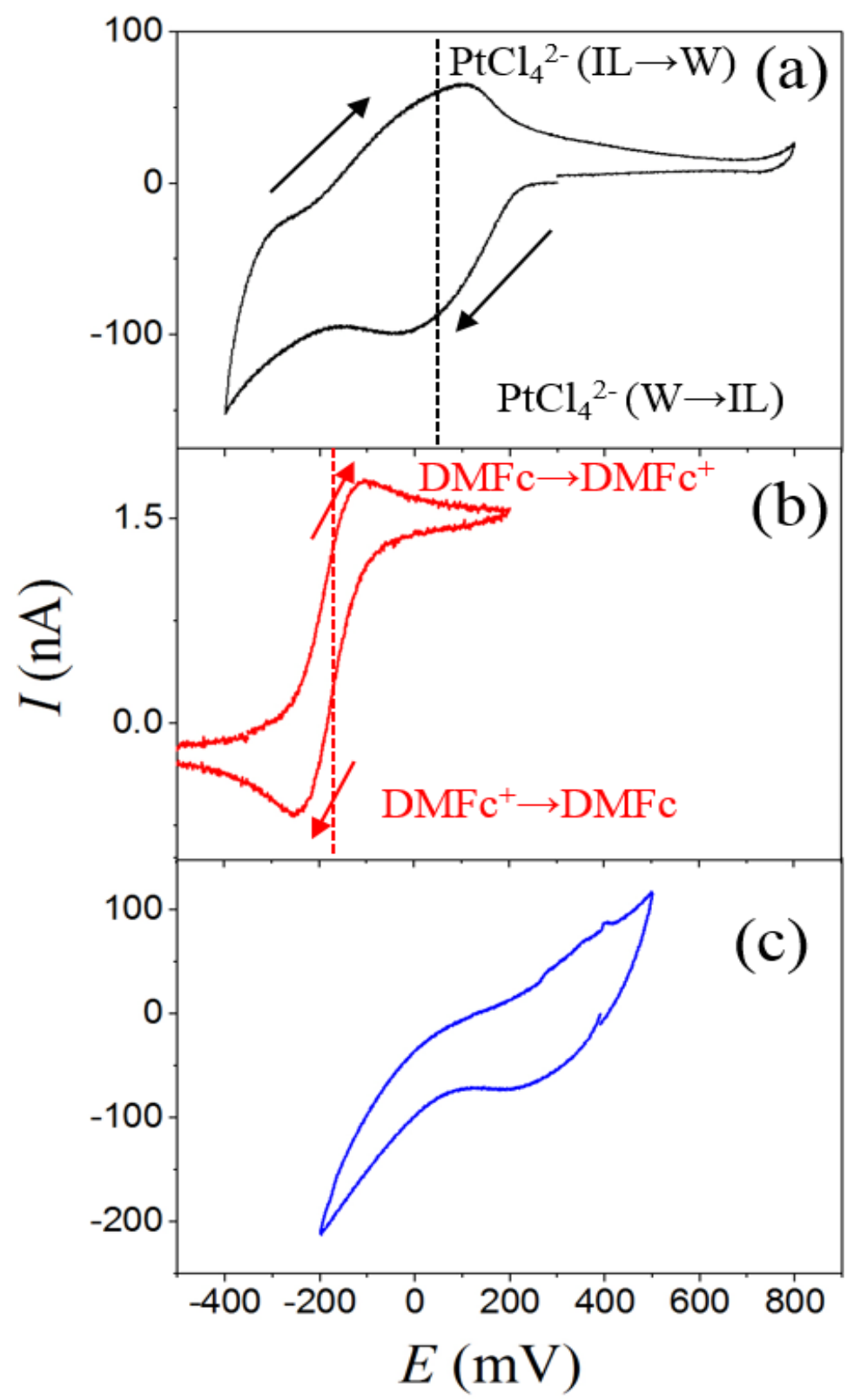

Figure 2. Cyclic voltammograms at the IL/W interface (a) for the ion transfer recorded using Cell I (b) for the electron transfer recorded using Cell II and (c) for both of them using Cell I in the presence of DMFc (50 mM) in IL. Scan rate: $100 \mathrm{mV} / \mathrm{s}$. 

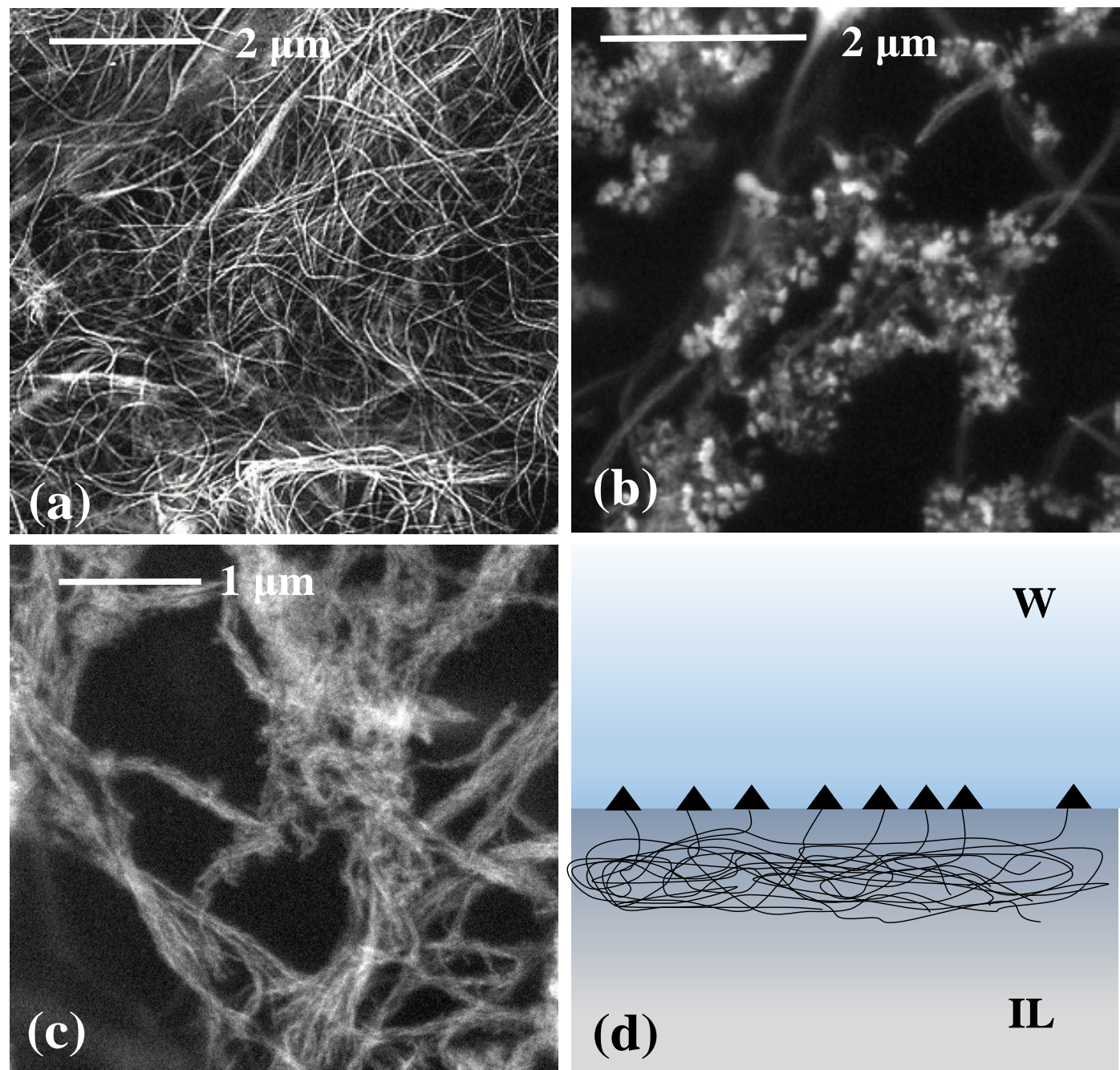

Figure 3. SEM images for (a) the Pt nanofibers formed at the IL/W interface; (b) growth situation of Pt nanofibers towards W; (c) growth situation of Pt nanofibers towards IL. (d) Schematic diagram for growth situation of Pt nanofibers in both W and IL. 

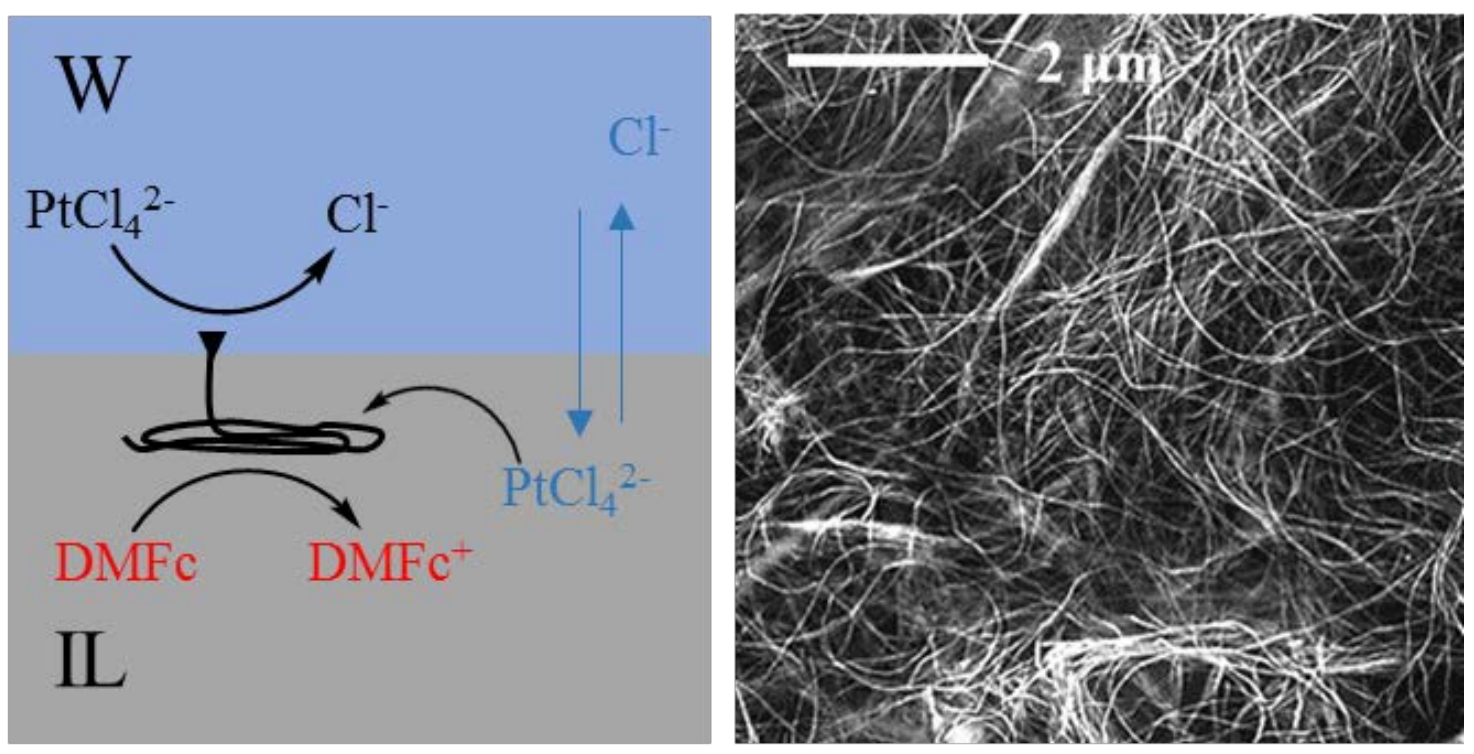

Graphical abstract 


\section{Highlights}

· Pt nanofibers were prepared by IL/W interfacial method.

- The successful preparation not only demonstrated the generality of the IL/W interface method, but also validated the reliability of our proposed mechanism.

-Electrochemical measurements revealed the mechanism where the spontaneous interfacial reaction can be decomposed to the IT of metal precursor and the ET between reducing agent and metal precursor across the IL|W interface.

-Electrocatalytic measurements of the Pt nanofibers for ORR manifested that the Pt nanofibers shows good prospect on PEMFCs field. 